\title{
PROCEEDINGS OF THE NUTRITION SOCIETY DIRECTIONS TO CONTRIBUTORS
}

The Nutrition Society will publish in its Proceedings papers presented by invitation at symposia of the Society and abstracts of original communications presented at other meetings.

Invitations to read papers at symposia are issued on the understanding that the persons invited send their papers for publication in the Proceedings of The Nutrition Society in the way outlined in the letter of invitation, at least a fortnight before the meeting, and that the papers will not be offered in that form for prior publication in any other journal.

Original communications presented at other meetings of the Society will be recorded in the Proceedings by means of an abstract not exceeding 400 words or the equivalent space in print. These abstracts should be submitted as stated in notices calling such meetings. The style of references, abbreviations, symbols and illustrations should be that of the Proceedings of The Nutrition Society.

General. Contributors who reside outside Great Britain are requested to nominate somebody in Great Britain willing to correct their proofs. They will receive by air mail an additional proof (but not the typescript) together with an order form for separates.

Authors' names should be given without titles or degrees. Women are requested to give one Christian name in full to avoid confusion. The name and address of the laboratory or institution from which the paper is published should be given. Any necessary descriptive material about the author should appear in parentheses after the author's name, or at the end of the paper, and not in the form of a footnote. Typescripts should carry the name and address of the person to whom the proof of the paper is to be sent.

Form of Papers Submitted for Publication. The onus of preparing a paper in a form suitable for sending to press lies in the first place with the author. Authors should consult a current issue in order to make themselves familiar with the practice of the Proceedings of The Nutrition Society as to typographical and other conventions, use of cross-headings, lay-out of tables, etc.

Papers should be in double-spaced typing on one side of sheets of uniform size with large margins. They should be written in English, the spelling being that of the Oxford English Dictionary.

References. References should be given in the text thus: Barnett \& Robinson (1942), (Culbertson \& Thomas, 1933); where a paper to be cited has more than two authors, the names of all the authors should be given when reference is first made, e.g. (Osborne, Mendel \& Ferry, 1919); subsequent citations should appear thus (Osborne et al. 1919). Where more than one paper by the same authors has appeared in one year the reference should be given as follows: Osborne \& Mendel (1914a); Osborne \& Mendel (1914b); or Osborne \& Mendel $(1914 a, b)$; (Osborne \& Mendel, 1914a, 1916; Barnett \& Robinson, 1942). At the end of the paper references should be given in alphabetical order according to the name of the first author of the publication quoted, names with prefixes being entered under the prefix, and should include the author's initials; the title of the paper should not be included. Titles of journals should be abbreviated as in the World List of
Scientific Periodicals (1952: 3rd ed. Oxford University Press). Examples of such abbreviations will be found in the current numbers of the Proceedings of The Nutrition Society and useful lists have recently been published in the Fournal of Physiology $(1952,116,1)$ and by the World Medical Association (World Medical Periodicals, 1957, 2nd ed. New York: World Medical Association). References to books and monographs should include the town of publication and the name of the publisher, as well as the date of publication and the number of the edition to which reference is made. Thus:

Barnett, J. W. \& Robinson, F.A. (1942). Biochem. F. 36, 364.

Culbertson, C. C. \& Thomas, B. H. (1934). Rep. Ia agric. Exp. Sta. 1933-4, p. 51.

Doisy, E. A., Somogyi, M. \& Shaffer, P. A. (1923). f. biol. Chem. 55, xxxi.

Fairey, N. H. (1938). Nature, Lond., 142, 1156.

Hennessy, D. J. (1941). Industr. Engng Chem. (Anal.), $13,216$.

King, H. (1941). F. chem. Soc. p. 338.

Osborne, T. B. \& Mendel, L. B. (1914a). F. biol. Chem. 17,325 .

Osborne, T. B. \& Mendel, L. B. (1914b). F. biol. Chem. 18,1 .

Osborne, T. B. \& Mendel, L. B. (1916). Biochem. $\%$. $10,534$.

Osborne, T. B., Mendel, L. B. \& Ferry, E. L. (1919). f. biol. Chem. 37, 233.

Starling, E. H. (1915). Principles of Human Physiology, 2nd ed. London: J. and A. Churchill.

Statistical Treatment of Results. In general it is not necessary to publish all the individual results of replicated tests. A statement of the number, their mean value and some appropriate measure of their variability is usually sufficient.

The methods of analysis followed should be indicated, but statistical details, such as tables of analysis of variance, should be given only if they are relevant to the discussion. A statement that the difference between the mean values of two groups of data is statistically significant should include an indication of the level of significance attained.

Illustrations. As a rule illustrations should be about twice the size of the finished block, each on a separate 
sheet, not larger overall than the sheets on which the paper itself is typed, and packed flat. Legends should be typed on a separate sheet and numbered correspondingly with the relevant illustrations. Each illustration, with its legend, should be comprehensible without reference to the text. The approximate position of each should be given in the text.

Diagrams and line drawings, which must all be originals, should be drawn in indian ink on Bristol board or on cartridge, tracing or faintly blue-lined paper. For general guidance in preparing diagrams, it is suggested that for a figure measuring 9 in. $\times 6$ in. all lines, axes and curves should have a thickness of $0.4 \mathrm{~mm}$, thus - In curves presenting experimental results the determined points should be clearly shown, the symbols used being, in order of preference, $O \bullet, \triangle \Delta, \square \square$, $x+$. For a 9 in. $\times 6$ in. figure, the diameter of the circles, the vertical height of the squares and equilateral triangles and the span of the crosses should be $1 / 8$ in. Curves and symbols should be drawn with a mechanical aid and not freehand, and should not extend beyond the experimental points. Scale marks on the axes should be on the inner side of each axis, 1/8 in. long, and should extend beyond the last experimental point. For plates, glossy photographs are required and clips should not be used.

A flyleaf of tracing paper should be firmly attached to each illustration. On it should be written in ink: $(a)$ the title of the paper and names of the authors; $(b)$ the figure or plate number; $(c)$ the figures and lettering which are to appear on the finished block, in their correct positions relative to the illustration.

The size of photomicrographs may have to be altered in printing. To avoid mistakes the magnification will be shown by a scale on the photograph itself, e.g. thus $1 \mu$. The scale with the appropriate unit should be drawn by the author on the flyleaf and will be inserted by the Press.

Tables. Tables should carry headings describing their content and should be comprehensible without reference to the text. The dimensions of the data, e.g. $\mathrm{g} / 100 \mathrm{ml}$, should be given at the top of each column and not repeated on each line of the table. Tables should not normally be included in the body of the text, but should be typed on separate sheets. Their approximate position in the text should be indicated.

Chemical Formulas. These should be written as far as possible on a single horizontal line. With inorganic substances, formulas may be used at the discretion of the editors. With salts it must be stated whether or not the anhydrous material is used, e.g. anhydrous $\mathrm{CuSO}_{4}$, or which of the different crystalline forms is indicated, e.g. $\mathrm{CuSO}_{4} .5 \mathrm{H}_{2} \mathrm{O}, \mathrm{CuSO}_{4} \cdot \mathrm{H}_{2} \mathrm{O}$.

Description of Solutions. Solutions of common acids, bases and salts are preferably defined in terms of normality $(\mathrm{N})$ or molarity (M), e.g. $\mathrm{N}-\mathrm{HCl} ; 0 \cdot 1$ $\mathrm{M}-\mathrm{NaH}_{2} \mathrm{PO}_{4}$. 'The term '\%' must be used in its correct sense, i.e. $\mathrm{g} / 100 \mathrm{~g}$ of solution. $10 \% \mathrm{HCl}$ means $10 \mathrm{~g}$ of hydrogen chloride in $100 \mathrm{~g}$ of aqueous solution, and should never be used to indicate a tenfold dilution of laboratory concentrated hydrochloric acid. For 'per cent

by volume', i.e. $\mathrm{ml} / 100 \mathrm{ml}$, the term ' $\%(\mathrm{v} / \mathrm{v})$ ' may be used. To indicate that a given weight of substance is contained in $100 \mathrm{ml}$ of solution, the term ' $\%(\mathrm{w} / \mathrm{v})$ ' may be used.

Nomenclature of Vitamins. The following names have been adopted by the Commission for the Reform of Nomenclature in Biological Chemistry of the International Union of Pure and Applied Chemistry and have been accepted by the Editors of the Proceedings of The Nutrition Society :

\section{Present name}

Vitamin $\mathrm{D}_{2}$ or calciferol

Vitamin $\mathrm{D}_{s}$

Vitamin E

Vitamin $B_{1}$, aneurin or thiamine

Vitamin $\mathrm{B}_{2}$ or riboflavin

Vitamin $P P$, niacinamide or nicotinamide

Vitamin $\mathrm{B}_{12}$

Vitamin $B_{12 b}$

Vitamin $\mathrm{B}_{12 c}$

Vitamin $\mathrm{C}=$ ascorbic acid

The Editors of the Proceedings of The Nutrition Society wish to retain the old, more comprehensive names of vitamin $D$, vitamin $E$, vitamin $B_{1}$, vitamin $B_{12}$ and vitamin $C$ to cover the biological activity where more than one active substance is or may be concerned.

The names vitamin $A\left(A_{1}, A_{2}\right)$ pantothenic acid, biotin, $p$-aminobenzoic acid and choline remain unchanged.

The names for vitamin $K$, the pyridoxine group, inositol and the folic-acid group have not yet been settled.

*This name has the advantage of permitting other $D$ vitamins, derived from 7-dehydrosterols, to be named by analogy through the use of the appropriate prefix.

IIn addition, the Editors of the Proceedings of The Nutrition Society propose always to use nicotinic acid and not niacin.

fThis name is recommended for adoption because it conforms to Werner's nomenclature for cobalt coordination complexes, and because it provides a system of terminology which may be extended, by analogy, to many modified cobalamins.

Nomenclature of Micro-organisms. Bacteria. Scientific names of bacteria should be binomials, the generic name only with a capital, and should be underlined once (for italic) in the typescript. Names for new species of genera, or new combinations of generic and specific names, should be formed in accordance with the International Bacteriological Code published in F. Bact. 1948, 55, 287, and (in 1949) in Int. Congr. Microbiol. Iv (1948), Copenhagen, p. 587. Wherever possible the names of recognized species should be those used in Topley \& Wilson's Principles of Bacteriology and Immunity (1955: 4th ed. London: Edward Arnold and Co.). However, where authors wish for good reasons to use some other name (e.g. one used in Bergey's Manual of Determinative Bacteriology, 1957: 7th ed. London: Baillière, Tindall and (Cox), the Topley \& Wilson name should be inserted in parentheses at the 
first citation thus: Serratia marcescens (Chromobacterium prodigiosum).

A name must be given in full at the first mention in a paper; in subsequent mention the generic name may be abbreviated, but the abbreviations must be unambiguous Single letter abbrevations should, in general, be avoided (thus: Staph. aureus, Strep. pyogenes, not $S$. aureus, $S$. pyogenes). When the generic name is used to define a group it should have a capital but should not be italicized; trivial names, or generic names used as adjectives, should not have capitals or be italicized. Examples of 'trivial names' are: staphylococci, streptococci, and meningococci or meningococcus (generic name is Neisseria). Staphylococcus and Streptococcus are generic names and the following passage illustrates the correct usage. 'This investigation is concerned with Salmonella enteritidis, because this Salmonella is important as a cause of disease in man and, because of experimental salmonella infections in the mouse, it is the most easily controlled. Tests with staphylococci, including Staph. aureus, have not contributed to the understanding of susceptibility to staphylococcal infection.'

Microfungi should be designated as in Ainsworth \& Bisby's $A$ dictionary of the Fungi (1954: 4th ed. Kew: Commonwealth Mycological Institute).

Other Nomenclature, Symbols and Abbreviations. Authors should follow current numbers of the Proceedings of The Nutrition Society in this connexion. The chemical nomenclature adopted is that followed by the Chemical Society (see f. chem. Soc. 1936, p. 1067; Mitchell, A. D., 1948, British Chemical Nomenclature, London: Edward Arnold and Co.; and Proc. chem. Soc., Lond., 1959, p. 4). For the nomenclature of amino acids Brit. $\mathscr{F}$. Nutr. 1953, 7, 1, should be consulted. The symbols and abbreviations are essentially those listed in British Standard 1991 : Part 1, General: Letter Symbols, Signs and Abbreviations (B.S. 1991: Part 1: 1954, 7s.). B.M.R. may be used for basal metabolic rate or basal metabolism.

Spectrophotometric terms and symbols are those proposed by the Society of Public Analysts and other Analytical Chemists (see Analyst, 1942, 67, 164). For mathematical notation and numerals the rules laid down in Proc. roy. Soc. A, 1909, 82, 14, should be followed. The attention of authors is particularly drawn to the following symbols: $m(=$ milli $)=10^{-3}$ and $\mu(=$ micro $)=10^{-6}$. Note also that $\mathrm{ml}$ (millilitres) should be used instead of c.c., and $\mu \mathrm{g}$ (micrograms) instead of $\gamma$.

Proofs. Proofs are sent to authors in order that they may make sure that the paper has been correctly set up in type, and not that they may add new material. Otherwise increased printing charges are inevitable. Excessive alteration may have to be disallowed. The symbols used to indicate corrections should be those laid down in British Standard 1219: 1945 (2s. 6d.); a shortened version is also published (B.S. 1219C: $1945,6 d$.

Reprints. Twenty-five reprints are supplied free of cost. Additional reprints may be purchased if the Printers are notified on the appropriate form immediately the proof of the paper is received.

For reprints of abstracts of communications see below.

Abstracts of Communications. Authors who wish to have summaries of papers read by them before The Nutrition Society recorded in the Proceedings must submit them in a final form as no proofs will be sent out. Reprints should be ordered direct from Lamport Gilbert \& Co. Ltd, 3-6 Gun Street, Reading, Berks. No free reprints are given. 